\title{
The Qualitative Dermatoglyphics PATTERNS in Both Hands for Males and Females in Ubang Clan Cross River State Nigeria
}

\author{
Andrew Donatus Abue ${ }^{1 *}$, Rose Christopher ${ }^{2}$, Adebisi Sunday ${ }^{3}$ \\ ${ }^{1}$ Department of Anatomical Sciences, College of Health Sciences, University of Abuja, Abuja, Nigeria \\ ${ }^{2}$ Clinicals, American International Medical University, Gros Islet, Saint Lucia \\ ${ }^{3}$ Department of Anatomy, Faculty of Medicine, Ahmadu Bello University, Zaria, Nigeria \\ Email: *andrew.abue@uniabuja.edu.ng
}

How to cite this paper: Abue, A. D. Christopher, R., \& Sunday, A. (2018). The Qualitative Dermatoglyphics PATTERNS in Both Hands for Males and Females in Ubang Clan Cross River State Nigeria. Advances in Anthropology, 8, 73-81. https://doi.org/10.4236/aa.2018.82004

Received: March 1, 2018

Accepted: May 27, 2018

Published: May 30, 2018

Copyright $\odot 2018$ by authors and Scientific Research Publishing Inc. This work is licensed under the Creative Commons Attribution-NonCommercial International License (CC BY-NC 4.0). http://creativecommons.org/licenses/by-nc/4.0/ cc) (i) (9) Open Access

\begin{abstract}
Dermatoglyphics patterns otherwise known as toe or fingerprints are defined as the scientific study of fingerprints or toe prints. This started in 1892 when one of the most original biologists of his time, Sir Francis Galton, a cousin of Charles Darwin published his now classic work on fingerprints. The Ubang community has a total population of about four thousand, six hundred (4600) people (2006 Census figures). They are four autonomous communities viz Okweriseng, New Jerusalem, Ofambe and Okiron. Their dominant religion is traditional religion and Christianity. They are mostly peasant farmers, located at the foot of the Obudu hills in Obudu LGA of Cross River State, Nigeria. This is an amazing Anthropological community where the Men speak Ofre and the women speak Arasere. The researchers were looking out for exceptional dermatoglyphics feature very unique to this community probably because of the unique language variation observed in the community. The researchers also aimed at establishing the qualitative dermatoglyphic features for the community. The ink procedure established by Cummins was adopted in collecting the prints on the palms and fingers of the selected sample size. A total of 800 persons were used for the research ( 400 males, 380 females and 20 samples were discarded). Inclusion and Exclusion criteria were used to select samples. The simple random sampling method was used in selecting the clusters and the subjects. Data were analyzed using SPSS for windows version 21 (IBM Corporation WY, USA) and Statistical Analysis System, SAS JMP10, user guide statistics, version 10 edition, SAS Institute Inc. Cary, North Carolina, USA. Descriptive statistics was generated for continuous and categorical variables; comparative analysis was done using analysis of variance. The re-
\end{abstract}


sults show a higher distribution of the Ulnar Loop in both Males and Females, followed by the Arches, then the whorls, finally the radial loops. This pattern of distribution follows the pattern of results obtained in various ethnic groups in Nigeria, Africa, Asia, Europe and America where the Men and Women speak the same Language (Oladipo et al., 2009). observed the relationship of Ovarian and Breast Cancers with high whorl percentage frequencies distribution in a population. Also there have established observations of the relationship of high Ulnar Loop percentage distribution with $\mathrm{ABO}$ blood group and Rhesus Positive distribution in a population. The research shows a higher percentage frequency distribution of the Arches and the arches have been linked with Myocardiac infarction (Rekha \& Senthil, 2012). There is need for Myocardiac infarction screening in the Community as well as other metabolic disorders investigations.

\section{Keywords}

Qualitative, Dermatoglyphic Patterns, Ubang Clan

\section{Introduction}

Dermatoglyphics patterns otherwise known as toe or fingerprints are defined as the scientific study of fingerprints or toe prints.

This started in 1892 when one of the most original biologists of his time, Sir Francis Galton, a cousin of Charles Darwin published his now classic work on fingerprints.

The study was later termed dermatoglyphics by Dr. Harold Cummins, the father of American fingerprint analysis. Dermatoglyphics is a Greek word, derma means skin and glyph means carving (Gupta et al., 2013). Fingerprint measuring parameters include 1) frequency of ridges in a particular pattern and 2) disposition of triradii (junctional area where three sets of parallel ridges meet). Fingerprint ridge pattern can be separated into three major types, arches, loops, and whorls. Arches have no triradii, loops have one triradii, and whorls have two or more triradii.

Herschel (1880) had reported that the Chief Magistrate of Hooghly district in Bengal, India was the first to use finger print identification against impersonation. He started the practice of recording fingerprints to prevent the impersonation of signatures. He first used fingerprints on native contract. He made a habit of requiring palm prints and later index and middle fingers on every contract made with the locals.

Dermatoglyphics is the process of taking the impression of papillary ridges of fingertips for analysis. Papillary ridges are confined to the palms and soles and flexure surfaces of the digits. These ridges form narrow parallel or curved arrays separated by narrow furrow. The aperture of sweat ducts opens at regular intervals along the summit of each ridge. 


\section{Comparative Anatomy}

It is estimated that humans, chimpanzees, and gorillas have more than 98 percent of their DNA in common. Primates are varied because they have adapted to diverse ecological niches. Some primates are active during the day; others, at night. Some eat insects; others, fruits; others, shoots, leaves, and bulk vegetation; and others, seeds or roots. Some primates live on the ground, others live in trees, and there are intermediate adaptations. However, because the earliest primates were tree dwellers, modern primates share homologies reflecting their common arboreal heritage (Figure 1).

\section{Embryology of the Upperlimbs}

The development of upper and lower limbs begins in fourth week of intrauterine life (Sant, 2005; Kiran et al., 2010) A pair of paddle-shaped projection appears on ventrolateral aspect of the embryo, opposite the lower cervical segments. These are the upper limb buds. Each of these limb buds consists of central core of mesoderm covered by ectoderm. The mesoderm is derived from somatic layer of lateral plate mesoderm. At the trip of the upper limb bud, the ectoderm thickens to form apical ectodermal ridge (AER), (Saddler et al., 1990; Sant, 2005). AER has an inductive effect on underlying mesoderm, which proliferate and limb bud starts growing.

Foetal volar pads are mound shaped elevations of mesenchymal tissue situated above the proximal end of the most distal metacarpal bone on each finger, in each interdigital area, in thenar and hyposthenia areas of the palms. Secondary foetal pads may be found on the central palm or as pairs on the proximal phalanges. The formation of these pads is first visible on the fingertips in the sixth to seventh week of embryonic development (Moore et al., 2006).

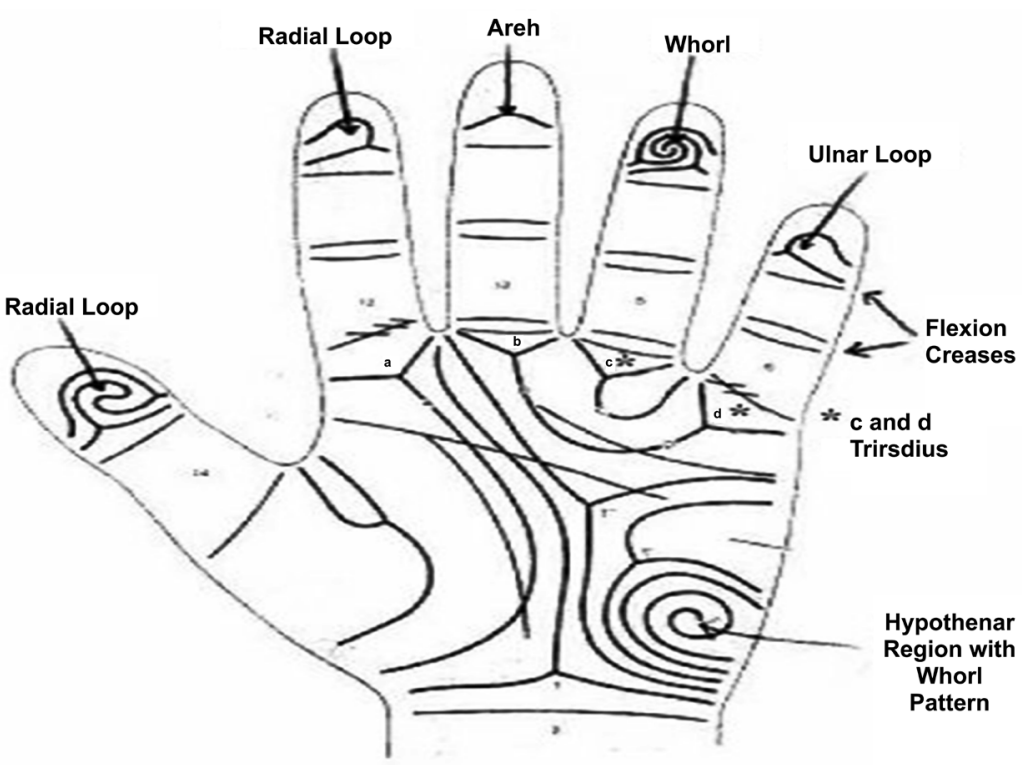

Figure 1. Dermatoglyphic configuration of the palm (Albert, 1999, Dermatoglyphics and Kabuki syndrome). 


\section{The Ubang Clan}

The Ubang community has a total population of about four thousand, six hundred (4600) people. They are four autonomous communities viz Okweriseng, New Jerusalem, Ofambe and Okiron. Their dominant religion is traditional religion and Christianity. They are mostly peasant farmers, located at the foot of the Obudu hills in Obudu LGA of Cross River State, Nigeria.

The Ubang clan is in Obudu LGA of Cross State on Latitude 9 degrees East, and longitude 6.3 degree North (Abue et al., 2018). The Ubang people are a gender sensitive linguistic clan. The community is about 18 kilometers off Bekwarra-Obudu road in northern Cross-Rivers and is bounded o in the North by the BETE speaking people of Obudu LGA, in the South by the Irruan speaking community of Boki LGA of Cross River State, in the East by Obanliku LGA of Cross River State, and in the West by Ogoja and Bekwarra LGAs. In Ubang males speak OFRE while the female folks speak Arasere. It is a faux pax for any of them to Cross borders.

\section{Materials and Method}

The aim of this study is to determine the qualitative dermatoglyphics patterns in men and women of Ubang clan.

Cross sectional simple random sampling method was adopted in selecting the clusters.

The Three clusters chosen include; 1) Okweriseng-300, 2) Ofambe-300 and 3) Okiron-200.

A total of eight hundred samples were collected from the three clusters.

The sample size for this study was obtained using the formula; [ $n=z^{2} \mathrm{pq} / \mathrm{d}^{2}$ ] (Naing, 2006).

Where: $\mathrm{n}=$ the desired sample size; $\mathrm{z}=$ the standard normal deviation, usually set at $1.96(=2.0) ; \mathrm{p}=$ the proportion in the target population having the particular trait (when no estimate $50 \%$ is used; i.e. 0.05 ); $q=1.0-p ; d=$ degree of accuracy desired, usually set at 0.04 . Therefore, $\mathrm{n}=(1.96)^{2}(0.5) /(0.04)^{2}=80$

\subsection{Materials}

1) Questionnaires and oral interviews used to establish the Language status of the Ubangs.

2) Carmel quick drying duplicating ink to collect the prints.

3) Inking slab.

4) Stamp pads for absorbing the ink.

5) Cotton wool for easy spread of the endorsing ink.

6) Duplicating papers (A4) for collection of the prints.

7) Water and soap for washing of hands.

8) Hand lens for magnifying and reading the ridges and patterns.

9) Protractor for measuring the ATD angles.

10) Pencil for recording and drawing. 
11) Pen for recording and drawing.

12) Ruler for marking the outlines.

13) Calculator.

14) Needle with a sharp point for counting the ridges.

15) Camera and voice recorder.

16) Research Assistants.

\subsection{Procedure for Analysis of Finger Prints}

The interpretation of prints was done according to Cummins et al. (1961) and by Penrose (1973) and includes identification of patterns.

Qualitative studies were carried out by studying the pattern-configuration on finger tips and inter digital areas. Finger patterns.

1) Whorls.

2) Radial loop.

3) Whorl loop.

4) Arch.

The digital and palmar prints of the subjects were taken using the duplicating paper through the ink procedure of Cummins et al. (1961) this method was selected because of the following advantages.

1) Simple technique.

2) Low cost.

3) Clarity of prints.

4) Less time consume.

\subsection{Steps in Obtaining the Prints}

The subjects were asked to clean their hands with soap and water. There were also asked to dry their hands but to leave some moisture.

1) Requisite amount of ink was rubbed on the stamp pad and was uniformly spread.

2) The left hand of the subject was placed on the stamp pad which is placed on a hard surface.

3) The left palm was examined for uniformity of the ink on the palmer surface of the hand.

4) The right hand of the subjects was placed on the sheet of paper kept over the firm board from proximal to distal end. The palm is gently pressed between inter-metacarpal grooves at the root of the fingers and on the dorsal side corresponding to the thenar and hypothenar eminence. The palm was then lifted from the paper in the reverse order from the distal to the proximal end. The fingers printed below the palmar print. The tip of the fingers was rolled from the radial to ulnar side to include all the patterns.

5) The same procedure were repeated for the left hand on a separate paper.

6) The print sheet were coded with research ID, age, sex and for group.

7) The prints were then subjected to detail dermatoglyphics analysis with the 
help of magnifying hand lens and the ridge counting were done with help of a sharp needle. The detail was noted on the same paper with pencil and pen.

8) The ink removed from the subject hands with the aid of about $1 \%$ HCL which will neutralize the ink.

9) Hand lens were used to magnify the ridges.

\section{Inclusion and Exclusion Criteria}

\subsection{Inclusion Criteria}

1) This research work includes persons whose grandparents and parents are of the Ubang clan paternally.

2) Age range is 18 - 68 years.

3) Clear prints.

\subsection{Exclusion Criteria}

1) This includes persons whose grandparents and parents are not from Ubang clan paternally.

2) Age range below 18 years and above 68 years.

3) Blurred prints.

\subsection{Statistical Analyses}

Data was analyzed using SPSS for windows version 21 (IBM Corporation WY, USA) and Statistical Analysis System, SAS JMP10, user guide statistics, version 10 edition, SAS Institute Inc. Cary, North Carolina, USA. Descriptive statistics was generated for continuous and categorical variables, comparative analysis was done using analysis of variance.

\subsection{Ethical Approval}

Ethical approval was obtained from the Faculty of Medicine's Committee on Ethics at the ABU Teaching Hospital Shika, Zaria, and Kaduna State ABUTH/HREC/K69/2014. (see Appendix vi). Permission to conduct the study was obtained from the community and the subjects involved in the research via verbal consultations and Approval.

\section{Result and Discussions}

Normal Distribution and Percentage Frequencies of the Male Dermatoglyphics Qualitative Features in Ubang Clan and Ntamante (Control).

Table 1 shows the true dermatoglyphics pattern of the males in Ubang clan of Cross River State, a linguistic gender sensitive community. The Ulnar loop were most prominent (51.1). The concentration was most on the left little fingers (109). The mean frequency was highest on the Ulnar Loop (51.1), followed by the Arch (16.9), Whorl (13.3), and radial loop (0.7).

Table 1 shows the percentage frequency distribution of the male patterns in Ubang clan of Cross river State, Nigeria; 
Table 1. Percentage frequency of male patterns in Ubang clan $(n=400)$.

\begin{tabular}{cccccccccccc}
\hline & I & II & III & IV & V & I & II & III & IV & V & Mean \pm SD \\
\hline Ulnar Loop & 27.3 & 18.3 & 19.5 & 2.75 & 0.75 & 24.3 & 13.5 & 16.8 & 3.3 & 3 & $13 \pm 9.8$ \\
Radial Loop & 0 & 0 & 0.5 & 0.5 & 0 & 0 & 0.5 & 0.5 & 0.5 & 0.3 & $0.3 \pm 0.2$ \\
Whorls & 0 & 3.3 & 2.8 & 4.3 & 5 & 1 & 3.5 & 2.5 & 2.5 & 3.3 & $2.8 \pm 1.5$ \\
Arch & 1.3 & 1 & 1.3 & 1.5 & 17 & 6.3 & 1.8 & 3 & 1 & 8.3 & $4.3 \pm 5.1$ \\
\hline$P<0.05$. & & & & & & & & & & &
\end{tabular}

The Ulnar Loop had the highest percentage frequency distribution, the distribution was more on the $1^{\text {st }}$ fingers of both hands (27.3\% Left hand, $24.3 \%$ Right hand).The least distribution for the Ulnar loop pattern was on the $5^{\text {th }}$ fingers in both hands (0.75\% Lefthand, 3\% Righthand). The Mean standard deviation for the Ulnar Loop was $13 \pm 9.8$ which shows significant differences in the Ulnar loop patterns in both hands.

The Radial Loop was the Least in distribution with a Mean Standard deviation of $0.3 \pm 0.2$. The Arch Pattern were next in distribution after the Ulnar Loop with a mean standard deviation of $4.3 \pm 5.1$. The distributions of these Arch patterns were more on the $5^{\text {th }}$ fingers (17\% Lefthand, 8.3\% Righthand).

In conclusion, there is significant differences in the qualitative variables of the palm amongst the Males in Ubang Clan of Cross River State, Nigeria. Hence, the Null hypothesis is rejected.

Table 2 shows the percentage Frequency Distribution of the Females of Ubang Clan of Cross River State Nigeria, the highest distribution of the qualitative variables in the various fingers in each hand are as follows in the order highest distribution.

1) Ulnar Loops (29.4\% Lefthand, 30.8\% Righthand) $1^{\text {st }}$ Fingers of both hands.

2) Arches (7.6\% Lefthand, $7.6 \%$ Righthand) $5^{\text {th }}$ Fingers of both hands.

3) Whorls (4.2\% Lefthand, 6.6\% Righthand) the fingers of highest frequencies are not the same on both hands as observed in the above patterns.

4) Radial Loops ( $10 \%$ on the Lefthand, $0 \%$ on the Right hand) $10 \%$ of radial loop was found on the $4^{\text {th }}$ digit. None was found in any other digit in both hands.

The Mean standard deviation shows significant differences in all the qualitative variables with the Ulnar Loop being the highest $(15.3 \pm 10.5)$ while the Radial Loop $(0.9 \pm 3.0)$ remains the Least.

The qualitative variables amongst the females in Ubang Clan shows Significant differences with characteristically higher values in the distribution of the radial loops. The qualitative valuables in females have a higher Mean Standard deviation $(15.3 \pm 10.5)$ compared to the qualitative variables in the Males (13 \pm 9.8).

The distribution of the qualitative variables amongst the males and females in terms percentage frequencies distribution is same as what is observed in other ethnic communities in Nigeria, Africa and Europe where the Men and women speak same Language as observed by the following Authors Dankmeijer et al., 
Table 2. Percentage frequency of female patterns in Ubang clan $(\mathrm{n}=380)$.

\begin{tabular}{|c|c|c|c|c|c|c|c|c|c|c|c|c|c|}
\hline & I & II & III & IV & V & I & II & III & IV & $\mathrm{V}$ & Mean \pm SD & Median & T-Test \\
\hline Ulnar Loop & 29.7 & 25.8 & 11.1 & 2.1 & 6.3 & 30.8 & 24.2 & 10.3 & 5.8 & 7.1 & $15.3 \pm 10.5$ & 11.1 & 0.0007 \\
\hline Radial Loop & 0 & 0 & 0 & 10.0 & 0 & 0 & 0 & 0 & 0 & 0 & $0.9 \pm 3.0$ & 0 & 0.3329 \\
\hline Whorls & 4.2 & 4.2 & 3.7 & 3.7 & 3.4 & 3.9 & 6.3 & 6.6 & 5 & 2.6 & $4.4 \pm 1.2$ & 4.2 & 0.0001 \\
\hline Arch & 3.4 & 2.6 & 4.2 & 4.2 & 7.6 & 2.6 & 3.1 & 4.2 & 3.4 & 7.6 & $4.3 \pm 1.8$ & 4.2 & 0.0001 \\
\hline
\end{tabular}

1962; Penrose et al., 1973.

Oladipo et al observed that increased whorl patterns increases the risk for Ovarian and breast Cancer. In this population (Ubang) the percentage frequencies the of the Whorl patterns is less. It has been established that populations with in high percentage frequencies with loop patterns have increased distribution of $\mathrm{ABO}$ blood group and Rhesus positive blood group.

\section{Conclusion}

This research work establishes the qualitative variables of the Ubangsh, it showed a higher percentage frequency distribution of the Ulnar Loop in both males and females. The females have higher distribution than the males. The population has high percentage frequency of the Arches compared with the whorls. It can be stated here that with the percentage frequency of patterns distribution in the Community, it is expected a high population of ABO blood group and Rhesus positive persons and less incidence of ovarian and Breast Cancers. Schaumann \& Alter (1983) and Rekha \& Senthil (2012) observed that a higher percentage frequency distribution of Arches is associated with Myocardial infarction. This research work observed a higher percentage frequency of arches in the population, there is a strong index of suspicion for Myocardial infarction to occur in this population.

\section{Recommendation}

1) There should more research work in screening for $A B O$ blood group in the population using qualitative variables of the hand.

2) There should be more research work in screening for Ovarian \& Breast Cancers using qualitative variables of the hands.

\section{References}

Abue, et al. (2018). Analysing the ATD Angle Percentage Distribution in Ubang Clan of Obudu LGA, Cross River State. J Anat Sci, 9, No. 1.

Albert, C. (1999). Kabuki Syndrome Clinical Genetics (pp. 105-177). Hoboken: Wiley Online Publications.

Cummins, et al. (1961). Finger Prints, Palms and Soles: An Introduction to Dermatoglyphics. Mineola, New York: Dover Publications.

Dankmeijer, J. (1962). Some Anthropological Data on Finger Prints. American Journal of 
Physical Anthropology, 23, 377. https://doi.org/10.1002/ajpa.1330230402

Gupta, R. K., \& Gupta, A. K. (2013). New, Easy and Effective Method to Take Dermatoglyphic Prints. National Journal of Medical Research, 3, 45-47.

Herschel, W. J. (1880). On the Skin Furrows of the Hand. Scientific Journal "Nature", 23, 79. https://doi.org/10.1038/023076b0

Kiran, K., Rai, K., \& Hegde, A. M. (2010). Dermatoglyphics as a Noninvasive Diagnostic Tool in Predicting Mental Retardation. Journal of International Oral Health, 2, No. 1.

Moore, K. L., \& Dalley A. F. (2006). Upper Limb. Clinically Oriented Anatomy (5 ed., 674-675). Philadelphia: Lippincott Williams and Wilkins.

Naing, et al. (2006). Practical Issues in Calculating the Sample Size for Prevalence Studies. Archives of Orofacial Sciences, 1, 9-14.

Oladipo, G. S., Paul, C. W., Bob-Manuel, I. F., Fawehimi, H. B., \& Edibamode, E. I. (2009). Study of Digital and Palmar Dermatoglyphic Patterns of Nigerian Women with Malignant Mammary Neoplasm. Journal of Applied Biosciences, 15, 829-834.

Penrose, L. S., \& O'Hara, P. T. (1973). The Development of Epidermal Ridges. Journal of Medical Genetics, 10, 201-208. https://doi.org/10.1136/jmg.10.3.201

Rekha, P., \& Senthil, K. S. (2012). A Study of Dermatoglyphic Patterns in Myocardiac Infarction. International Journal of Anatomical Sciences, 3, 08-10.

Saddler, T. W. (1990). Langman’s Medical Embryology (6th ed., p. 400). Baltimore: Williams and Wilkins.

Sant, S. (2005). Embryology for Medical Students (2nd ed., pp. 81-85). Jaypees Brothers Medical Publishers(P)Ltd.

Schaumann, B., \& Alter, M. (1983). Dermatoglyhics in Medical Disorder Oxford Monograph on Medical Genetics (pp. 146-172). Bodmin, Comwell: Hartnoil Print. 